\title{
Behaviour of Bamboo Leaf Ash Blended Cement Concrete in Sulphates Environment
}

\author{
Ademola S.A ${ }^{1}$, Buari T.A ${ }^{2}$ \\ ${ }^{\text {I}(D e p a r t m e n t ~ o f ~ B u i l d i n g ~ T e c h n o l o g y, ~ O s u n ~ S t a t e ~ P o l y t e c h n i c, ~ P . M . B ~ 301, ~ I r e e, ~ S t a t e ~ o f ~ O s u n, ~ N i g e r i a) ~}$ \\ ${ }^{2}$ (Department of Building Technology, Federal Polytechnic, P.M.B 231, Ede, State of Osun, Nigeria)
}

\begin{abstract}
This paper presents the characteristic strength behaviour of Bamboo Leaf Ash (BLA) blended cement concrete in sulphate environment. A total of 66 concrete cubes of $150 \mathrm{~mm}$ x $150 \mathrm{~mm} \times 150 \mathrm{~mm}$ were produced with OPC-BLA blended cement, the partial replacement of OPC by BLA was varied from $0 \%$ to $15 \%$ in the concrete. The specimens were tested and crushed to obtain their compressive strengths at age 21 , and 28 days of curing in different media ( $\mathrm{Na} 2 \mathrm{SO} 4, \mathrm{CaSO} 4 \mathrm{a}$ and $\mathrm{MgSO} 4$ at $0.5 \%, 1.5 \%$ and $2.5 \%$ concentration). The choice of the percentage concentration of chemicals used as curing media was based on a similar research carried out by [1-2]. The 28 days strengths obtained for 5\%,10\% and $15 \%$ replacement of BLA increases when compared with the results obtained at 21 days. The results also increased as the concentration of the sulphate increases, it shows that very high concrete strength values could be obtained with OPC-BLA blended cement concrete when high control measures are applied and at longer days of hydration and in sulphate environment. Therefore, OPC/BLA blended cement concrete could be used in civil engineering and building works in sulphate environment and where early strength is not a major requirement, thereby reducing the cost of production.
\end{abstract}

Keywords: - Compressive strength, Concentration, Sulphates, Bamboo leaf Ash, Blended cement concrete.

\section{INTORDUCTION}

There is growing interest to recycle waste materials by using them to modify concrete mixes. Several works have been done in the area of adding and replacing the cement with different pozzolans to improve mechanical strength and durability of concrete [3-4]. It is generally known that Portland cement based concrete materials are limited by their negative environmental impact arising from cement production. Portland cement production is considered as a major contributor to greenhouse gas emission known to be a major cause of global warming [5-6]. The cement products are also faced with durability problems which impact on resource utilization for reconstruction and maintenance [6].The incorporation of agricultural by-product pozzolans has been studied with positive results in the manufacture and application of blended cements. [7-8] found good prospect in partially replacing cement with periwinkle shell ash in river stone aggregate concrete. [1] Successfully applied groundnut shell ash as partial replacement for cement in concrete production in a sulphates environment

With these reasons, this work evaluates the characteristics strength performance of bamboo leave ash (BLA) as a partial replacement for ordinary Portland cement (OPC) in concrete. Various percentages of BLA $(0 \%, 5 \%, 10 \%, 15 \%$.) were used to produce the concrete and BLA/OPC concretes characteristics performance were measured after curing in water for 28 and 56 days hydration periods by conducting Compressive and splitting tensile tests on the hardened concretes. The choice of the percentage substitutions (BLA) used and hydration period were based on a similar research carried out by [1] Characteristics Strength and Durability of Groundnut Shell Ash (GSA) Blended Cement Concrete in Sulphate Environments, [9] Factors Influencing the Sulphate Resistance of Cement Concrete and Mortar and [10] on Bambara Groundnut Shell Ash which, they reported that $10 \%$ substitution of pozzolans with cement in blended concrete was acceptable compared with required standards.

\section{MATERIALS AND METHOD}

The materials used for this research work are mainly cement, water, aggregate (granite and sand), and Bamboo Leaf Ash (BLA). These materials were used for casting of $150 \mathrm{mmx} 150 \mathrm{mmx} 150 \mathrm{~mm}$ concrete cubes.

The methodology involved field and laboratory tests which comprises the collection of the materials and casting of concrete cubes. The concrete cube contains $0 \%$ of bamboo leave ash as the control sample and $5 \%, 10 \%$ and $15 \%$ of BLA percentage replacement were used for the research work. The practical work was carried out at the Concrete and Structural Laboratory of the Department of Building, Federal Polytechnic, Ede. The sieve analysis, moisture content and the specific gravity were carried out on GSA at the Soil Mechanics 
Laboratory of the Department of Building, Federal Polytechnic, Ede. The results of chemical analysis and physical properties of OPC/BLA are presented in table 1, while specific gravity of BLA is presented in tables 2 . The aggregates used were of high quality and free of deleterious organic matter and the $20 \mathrm{~mm}$ and $4.75 \mathrm{~mm}$ sieve sizes were used for coarse and fine aggregates respectively.

\subsection{Mixes}

A concrete mix of ratio 1:2:4 was adopted for the production of concrete cubes at water / cement ratio of 0.6. Cement content was replaced at 5\%,10\% and $15 \%$ with BLA. The adopted substitution levels was based on previous similar works conducted by $[1,2,7,9]$ which Recommends between $10 \% 40 \%$ as the most suitable replacement level for Blended concrete. The moulds used were cleaned with black engine oil to prevent the development of bond between the mould and the concrete. The freshly mixed concrete was scooped into the mould. Each mould was filled in three layers with the concrete; each layer was rammed 25 times with a tamping rod. $150 \mathrm{~mm} \times 150 \mathrm{~mm} \times 150 \mathrm{~mm}$ cubes were produced for the tests. A total of 80 cubes were cast. Concrete cubes were stripped from the mould carefully after 24 hours of the concrete setting under air. All the cubes were cured in water for hydration period of 21 and 28 days respectively. Averages of three cubes were crushed for each test. The results of the analysis are shown in Tables 5.0-5.5 and Figures 1.0-6.0

\subsection{Setting Time}

Values obtained as initial setting time for OPC and OPC/GSA pastes were 2 hours 35 minutes and 3 hours 05 minutes respectively. Final setting time values were obtained for OPC and OPC/GSA pastes as 3 hours 15 minutes and 4 hours 12 minutes. The setting time values obtained were within the recommended range of 30 minutes to 10 hours stipulated by [11] and slightly different from result obtained by [1,2] in similar work.

\subsection{Curing Condition}

Curing conditions of concrete influence its hydration process. For full hydration of binder and strength development in the concrete the continuous, longer and moist curing is required. In this work, the Initial curing condition which affects the Sulphate resistance of concrete or mortar were carefully done in curing tank with samples totally immersed in the curing mediums for the target hydration periods.

\subsection{Splitting Tensile Test}

Splitting tensile test was conducted at the Mechanical Laboratory of the Federal Polytechnic, Ede After the specimens had been cured for the proper length of time in the water tank, the immersed specimens were taken out from water and allowed to dry. The machine was set for the required range and diametrical lines was drawn on the two ends of the specimen to ensure that they are on the same axial place, after noting the weight and dimension of the specimen. A plywood strip was placed on the lower plate, then the specimen was placed above the lower plate and the other plywood strip was placed above the specimen. The specimen was loaded continuously without shock at uniform rates until failure occurred and the failure load was recorded.

The splitting tensile strength was calculated using the formula Tsp $=2 \mathrm{P} /$ pi DL Where, $\mathrm{P}=$ applied load $\mathrm{D}=$ diameter of the specimen $L=$ length of the specimen

\subsection{Compressive Strength Test}

Before crushing, the cubes were brought out of the water and kept for exactly 30 minutes for the water to drip off. They were then taken to the crushing machine in accordance with [8]. The cubes were crushed, a result of the load applied by the crushing machine and the readings were taken.

Compressive Stress $=$ Applied Load $(\mathrm{N})$

Cross sectional Area of specimen $\left(\mathrm{mm}^{2}\right)$

\subsection{Chemical and Physical Properties of Bamboo Leaf Ash}

\section{RESULTS AND DISCUSSIONS}

Table 1.0: Physical properties of Bamboo Leaf Ash

\begin{tabular}{|l|l|}
\hline Moisture content & $0.40 \%$ \\
\hline Specific gravity & 2.25 \\
\hline
\end{tabular}

\subsection{Specific Gravity}

Table 2.0: Determination of Specific Gravity

\begin{tabular}{|l|l|l|}
\hline Sample Weight $(\mathrm{g})$ & Test A $(\mathrm{g})$ & Test B $(\mathrm{g})$ \\
\hline W1 & 5.70 & 5.70 \\
\hline W2 & 10.60 & 10.70 \\
\hline W3 & 65.00 & 65.00 \\
\hline W4 & 62.28 & 62.23 \\
\hline GS & 2.25 & 2.24 \\
\hline
\end{tabular}

Source: laboratory work, 2013 
Average $S G=\frac{2.25+2.24}{2}$

Therefore: $\quad \mathrm{SG}=2.245$. Approximately $=2.25$

The Specific gravity of BLA is being 2.25 . This value is higher than 1.85 and 1.90 reported by $[1,12]$ and [13] for GSA and Pulverised Fuel Ash respectively. These values are less than average value of 3.15 for Portland cement. This means that a considerable greater volume of cementitious materials (BLA) will result from mass replacement. The moisture content is in agreement with value reported by [2] which was $0.42 \%$.

Table 3.0: Result of Chemical Properties of OPC and BLA

\begin{tabular}{|l|l|l|}
\hline Chemical Composition (\%) & OPC & BLA \\
\hline $\mathrm{SiO}_{2}$ & 22.13 & 75.90 \\
\hline $\mathrm{Al}_{2} \mathrm{O}_{3}$ & 3.74 & 4.13 \\
\hline $\mathrm{F}_{2} \mathrm{O}_{3}$ & 2.97 & 1.22. \\
\hline $\mathrm{CaO}$ & 63.36 & 7.47 \\
\hline $\mathrm{MgO}$ & 2.58 & 1.85 \\
\hline $\mathrm{K}_{2} \mathrm{O}$ & 0.52 & 5.62 \\
\hline $\mathrm{MnO}_{2}$ & 0.00 & 0.016 \\
\hline $\mathrm{P}_{2} \mathrm{O}_{5}$ & 0.00 & 3.22 \\
\hline True Density $\left(\mathrm{g} / \mathrm{cm}^{3}\right.$ & 2.97 & 2.25 \\
\hline
\end{tabular}

Source: laboratory experiment, 2013.

The results above indicate that BLA contains most of oxides found in ordinary Portland cement. The $\mathrm{CaO}$ composition of ordinary Portland cement was higher than that of the Bamboo leaf ash while $\mathrm{SiO}_{2}$ composition of BLA was also higher than that found in ordinary Portland cement. The result of the chemical analysis is similar to the works conducted by [2] with the total percentage of Iron Oxide, Silicon Oxide and Aluminum Oxide is less than the minimum of $70 \%$ specified by for pozzolanas [1,7].

Table 4.0: Results of slump test on concrete with BLA partial replacement (1:2:4 mixes)

\begin{tabular}{|l|l|l|l|l|}
\hline OPC/BLA & $0 \%$ & $5 \%$ & $10 \%$ & $15 \%$ \\
\hline Slump 1:2:4 mix (mm) & 30 & 22.5 & 18.2 & 15.5 \\
\hline
\end{tabular}

The table above shows that the slump decreases with increasing \%BLA replacement.

Table 5.0: Compressive Strength of BLA blended Cement Concrete Cured in $\mathrm{H} 2 \mathrm{O}$ and $0.5 \%, 1.5 \%$ and $2.5 \%$ Solution of CaSO4 at age 21days of hydration.

\begin{tabular}{|l|l|l|l|l|}
\hline \multirow{2}{*}{ Description } & \multicolumn{4}{l}{ Compressive Strength In $\left(\mathrm{N} / \mathrm{mm}^{2}\right)$} \\
\cline { 2 - 5 } & water & $\mathbf{0 . 5 \%} \mathbf{C a S O}_{\mathbf{4}}$ & $\mathbf{1 . 5 \%} \mathbf{C a S O}_{\mathbf{4}}$ & $\mathbf{2 . 5 \%} \mathbf{C a S O} \mathbf{4}_{\mathbf{4}}$ \\
\hline BLA $_{\mathbf{0}}$ & 21.64 & 20.85 & 20.06 & 20.03 \\
\hline BLA $_{\mathbf{5}}$ & 15.60 & 13.46 & 17.14 & 17.02 \\
\hline BLA $_{\mathbf{1 0}}$ & 16.98 & 16.19 & 16.31 & 17.89 \\
\hline BLA $_{\mathbf{1 5}}$ & 12.93 & 14.02 & 14.31 & 15.00 \\
\hline
\end{tabular}

$\mathrm{BLA}_{0}, \mathrm{BLA}_{5}, \mathrm{BLA}_{10}$ and $\mathrm{BLA} \mathrm{A}_{15}$ are; 0\%, 5\%, $10 \%$ and $15 \%$ Bamboo Leaf Ash replacements

The result in table 5.1 indicates that concrete with Ordinary Portland Cement at age 21 days reduces in CaSO4 solution, while BLA blended Cement Concrete performed better with increase in strength at different concentration of $\mathrm{CaSO} 4$. The above result may be due to the form of Ettringite developed in the cement paste which depends on phase of Calcium Aluminates' Hydrates.

Figure 1.0: Compressive strength of samples in water and $\mathrm{CaSO}_{4}$ at 21 days hydration period 


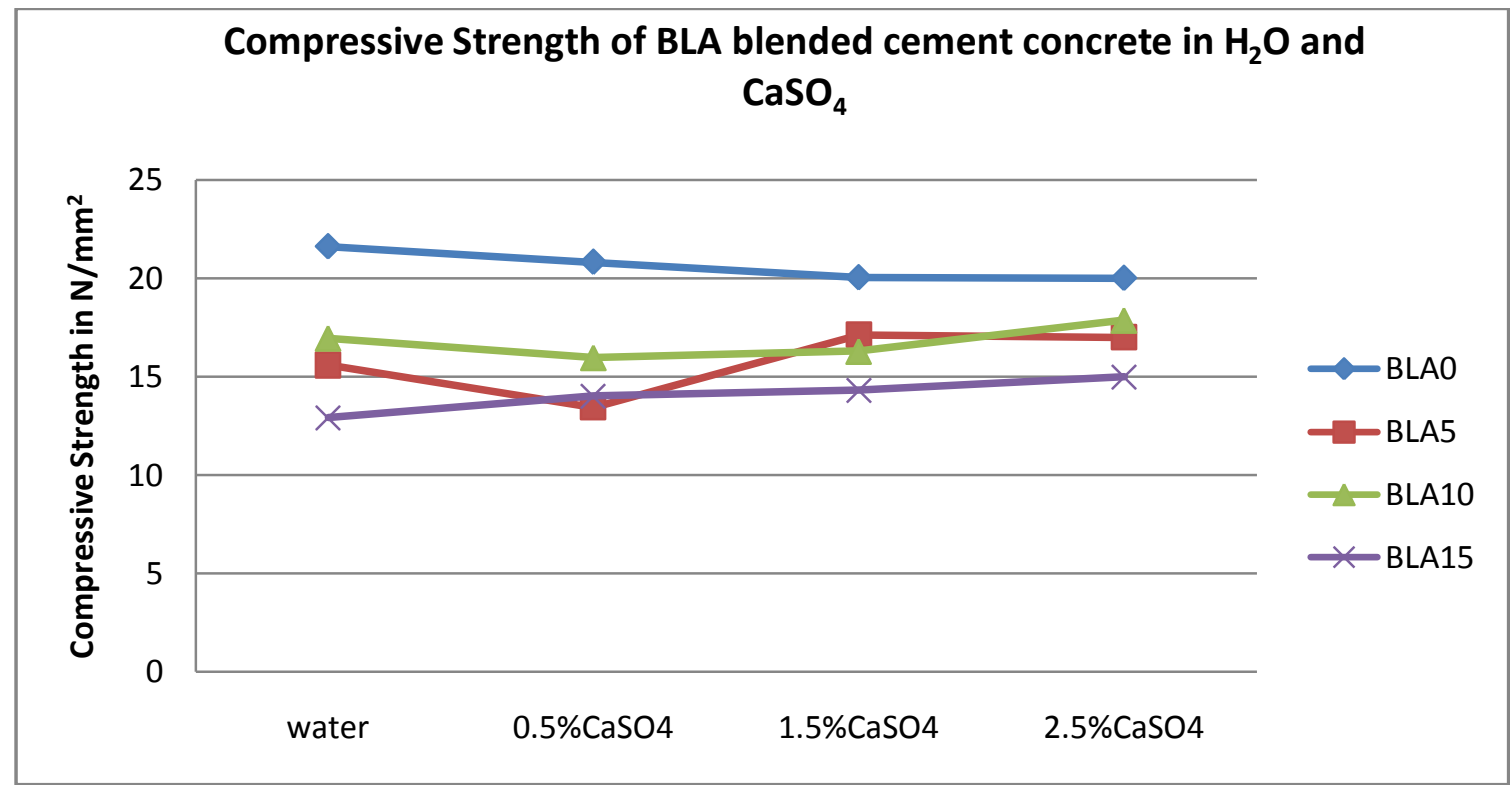

Table 5.1: Compressive Strength of BLA blended Cement Concrete Cured in $\mathrm{H}_{2} \mathrm{O}$ and $0.5 \%$, $1.5 \%$ and $2.5 \%$ Solution of $\mathbf{N a}_{2} \mathbf{S O}_{4}$ at age 21 days of hydration.

\begin{tabular}{|l|l|l|l|l|}
\hline \multirow{2}{*}{ Description } & \multicolumn{5}{l|}{ Compressive Strength $\mathrm{In}\left(\mathrm{N} / \mathrm{Mm}^{2}\right)$} \\
\cline { 2 - 5 } & water & $\mathbf{0 . 5 \%} \mathbf{N a}_{\mathbf{2}} \mathbf{S O}$ & $\mathbf{1 . 5 \%} \mathbf{N a}_{\mathbf{4}} \mathbf{S O}_{\mathbf{4}}$ & $\mathbf{2 . 5 \%} \mathbf{N a}_{\mathbf{2}} \mathbf{S O}_{\mathbf{4}}$ \\
\hline $\mathbf{B L A}_{\mathbf{0}}$ & 21.64 & 16.55 & 18.69 & 18.45 \\
\hline $\mathbf{B L A}_{\mathbf{5}}$ & 15.60 & 12.63 & 15.34 & 16.10 \\
\hline $\mathbf{B L A}_{\mathbf{1 0}}$ & 16.98 & 17.15 & 17.33 & 18.57 \\
\hline BLA $_{\mathbf{1 5}}$ & 12.93 & 14.35 & 14.59 & 13.98 \\
\hline
\end{tabular}

$\mathrm{BLA}_{0}, \mathrm{BLA}_{5}, \mathrm{BLA}_{10}$ and $\mathrm{BLA}_{15}$ are; 0\%, 5\%, 10\% and 15\% Bamboo Leaf Ash replacements

The result in the Table 5.2 of OPC and BLA blended cement concrete varies in $\mathbf{N a}_{2} \mathbf{S O}_{4}$ solution and water medium at 21 days hydration as shown in the table above. When the strength of OPC concrete cured in the same medium solutions reduces as the solution concentrations increases, the BLA blended cement concrete increases in the same media.

Figure 2.0: Compressive strengths of samples in water and $\mathrm{Na}_{2} \mathrm{SO}_{4}$ at the age of 21 days.

\section{Compressive Strength of BLA blended cement concrete in $\mathrm{H}_{2} \mathrm{O}$ and $\mathrm{Na}_{2} \mathrm{SO}_{4}$}

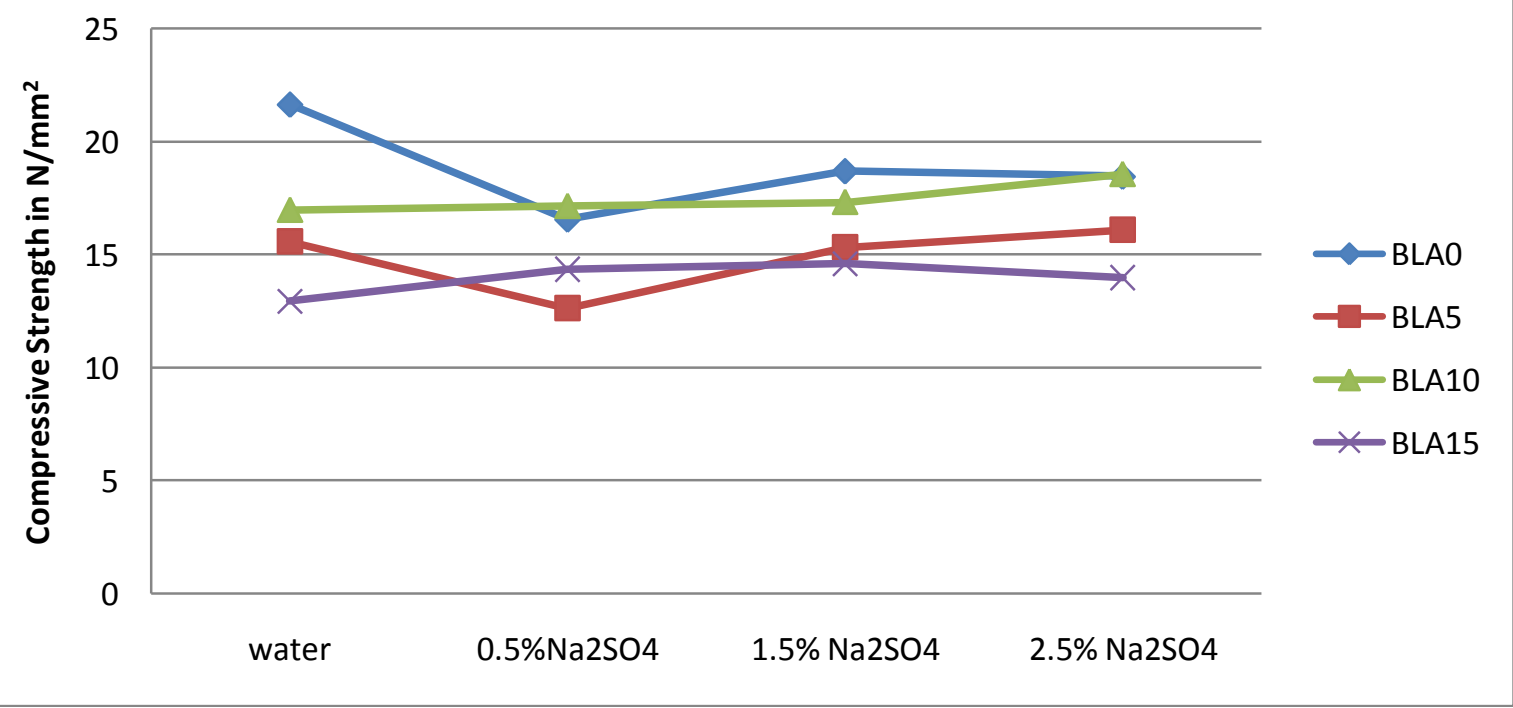


Table 5.2: Compressive Strength of BLA blended Cement Concrete Cured in $\mathrm{H}_{2} \mathrm{O}$ and $0.5 \%, 1.5 \%$ and $2.5 \%$ Solution of $\mathrm{MgSO}_{4}$ at age 21days of hydration.

\begin{tabular}{|l|l|l|l|l|}
\hline \multirow{2}{*}{ Description } & \multicolumn{4}{|l|}{ Compressive Strength In $\left(\mathrm{N} / \mathrm{Mm}^{2}\right)$} \\
\cline { 2 - 5 } & water & $\mathbf{0 . 5 \%} \mathbf{M g S O}_{\mathbf{4}}$ & $\mathbf{1 . 5 \%} \mathbf{M g S O}_{\mathbf{4}}$ & $\mathbf{2 . 5 \%} \mathbf{M g S O}_{\mathbf{4}}$ \\
\hline BLA $_{\mathbf{0}}$ & 21.64 & 15.46 & 15.29 & 14.68 \\
\hline BLA $_{5}$ & 15.60 & 15.91 & 15.63 & 16.22 \\
\hline BLA $_{10}$ & 17.08 & 17.28 & 19.88 \\
\hline BLA $_{15}$ & 16.98 & & & 13.37 \\
\hline
\end{tabular}

$\mathrm{BLA}_{0}, \mathrm{BLA}_{5}, \mathrm{BLA}_{10}$ and $\mathrm{BLA}_{15}$ are; 0\%, 5\%, $10 \%$ and $15 \%$ Bamboo Leaf Ash replacements

There is tremendous loss in compressive strength of OPC concrete cured in MgSO4 solution as shown in table 5.3 above when compared to the OPC concrete cured in water. The BLA blended cement concrete shows no sign of strength loss but rather increases in strength as the concentration of solution increases especially at 5\%, $10 \%$ and $15 \%$ BLA replacement, but that of $10 \%$ replacement is very significant. This may be attributed to the reaction between magnesium sulphate solution and cement paste forming gypsum $\left(\mathrm{CaSO} 4-32 \mathrm{H}_{2} \mathrm{O}\right)$ and Ettringite $\left(3 \mathrm{CaO}-\mathrm{Al}_{2} \mathrm{O}_{3}-3 \mathrm{CaSO}_{4}-32 \mathrm{H}_{2} \mathrm{O}\right)$.

Figure 3.0: compressive strength of samples in water and MgSO4 at 21 day hydration period

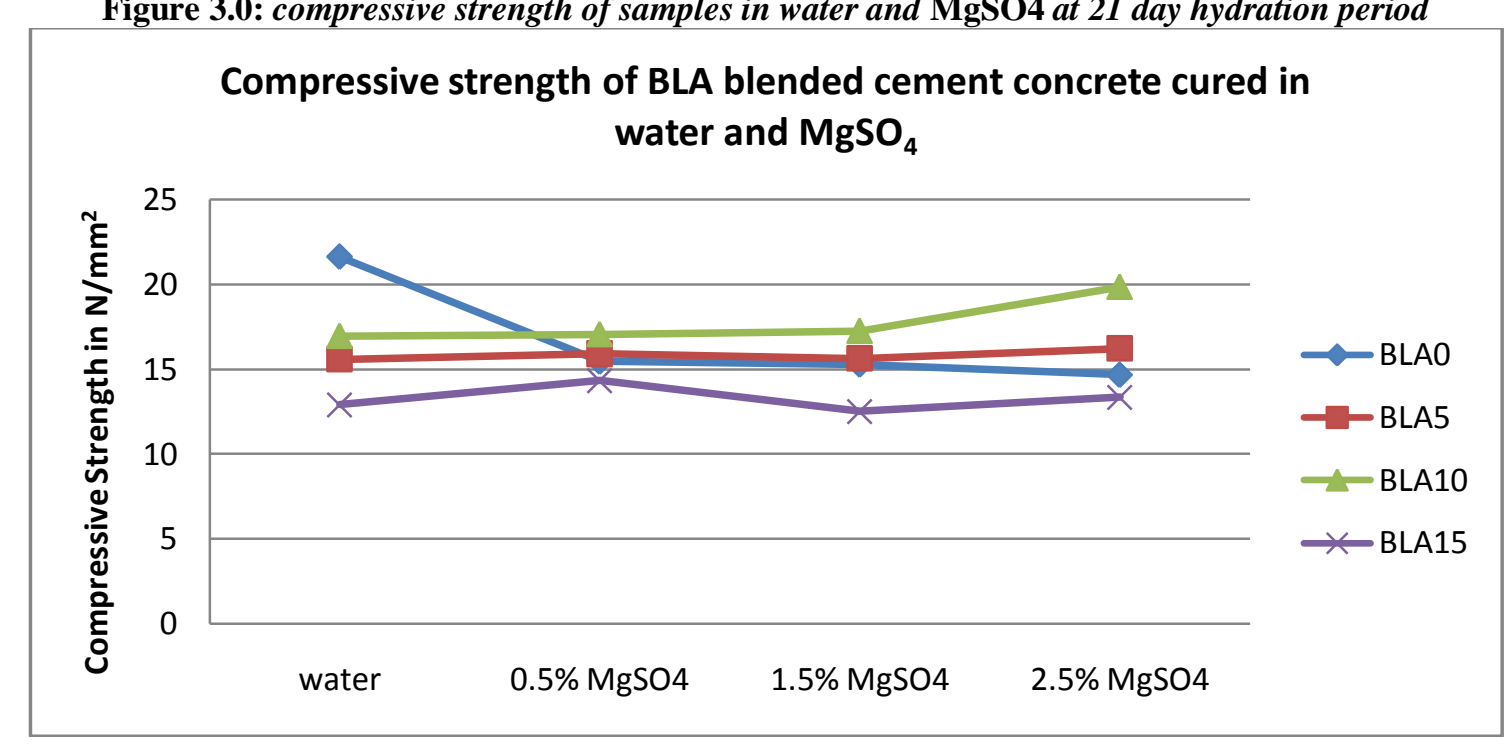

5.3: Compressive Strength of BLA blended Cement Concrete Cured in $\mathrm{H}_{2} \mathrm{O}$ and $0.5 \%, 1.5 \%$ and $2.5 \%$ Solution of $\mathrm{CaSO}_{4}$ at the age of 28days.

\begin{tabular}{|l|l|l|l|l|}
\hline \multirow{2}{*}{ Description } & \multicolumn{4}{|l|}{ Compressive Strength In $\left(\mathrm{N} / \mathrm{Mm}^{2}\right)$} \\
\cline { 2 - 5 } & water & $\mathbf{0 . 5 \%} \mathbf{C a S O}_{\mathbf{4}}$ & $\mathbf{1 . 5 \%} \mathbf{C a S O}_{\mathbf{4}}$ & $\mathbf{2 . 5 \%} \mathbf{C a S O}_{\mathbf{4}}$ \\
\hline BLA $_{\mathbf{0}}$ & 23.64 & 21.78 & 22.64 & 23.12 \\
\hline BLA $_{\mathbf{5}}$ & 18.69 & 15.23 & 18.03 & 17.84 \\
\hline BLA $_{\mathbf{1 0}}$ & 20.98 & 18.71 & 18.65 & 19.35 \\
\hline BLA $_{\mathbf{1 5}}$ & 15.93 & 15.06 & 14.21 & 15.24 \\
\hline
\end{tabular}

$\mathrm{BLA}_{0}, \mathrm{BLA}_{5}, \mathrm{BLA}_{10}$ and $\mathrm{BLA}_{15}$ are; 0\%, 5\%, 10\% and 15\% Bamboo Leaf Ash replacements

The result above indicates that OPC concrete gained more strength at 28 days of hydration over that of OPC/BLA blended cement concrete which does not show any strength improvement as one will expect.

Figure 4.0: Compressive strength of samples in water and $\mathrm{CaSO}_{4}$ at 28 day hydration period. 


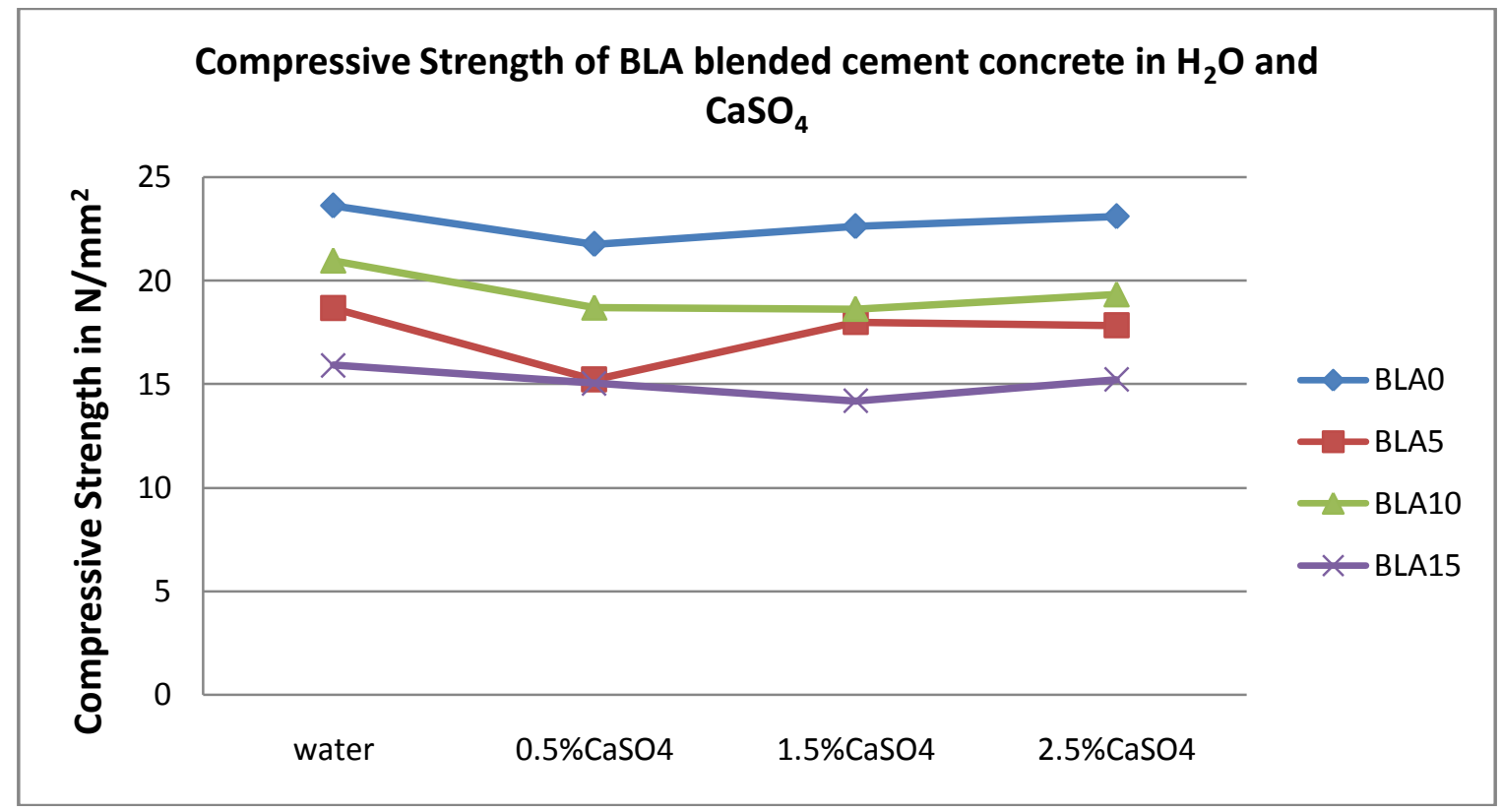

Table 5.4: Compressive Strength of BLA blended Cement Concrete Cured in water and 0.5\%, $1.5 \%$ and $2.5 \%$ Solution of $\mathrm{Na} 2 \mathrm{SO} 4$ at 28 days of hydration.

\begin{tabular}{|l|l|l|l|l|}
\hline \multirow{2}{*}{ Description } & \multicolumn{4}{|l|}{ Compressive Strength In $\left(\mathrm{N} / \mathrm{Mm}^{2}\right)$} \\
\cline { 2 - 5 } & water & $\mathbf{0 . 5 \%} \mathbf{N a}_{\mathbf{2}} \mathbf{S O}_{\mathbf{4}}$ & $\mathbf{1 . 5 \%} \mathbf{N a}_{\mathbf{2}} \mathbf{S O}_{\mathbf{4}}$ & $\mathbf{2 . 5 \%} \mathbf{N a}_{\mathbf{2}} \mathbf{S O}_{\mathbf{4}}$ \\
\hline $\mathbf{B L A}_{\mathbf{0}}$ & 23.64 & 20.80 & 21.03 & 21.82 \\
\hline $\mathbf{B L A}_{\mathbf{5}}$ & 18.69 & 14.52 & 17.10 & 17.96 \\
\hline BLA $_{\mathbf{1 0}}$ & 20.98 & 19.43 & 20.52 & 22.22 \\
\hline BLA $_{\mathbf{1 5}}$ & 15.93 & 16.61 & 17.93 & 19.14 \\
\hline
\end{tabular}

$\mathrm{BLA}_{0}, \mathrm{BLA}_{5}, \mathrm{BLA}_{10}$ and $\mathrm{BLA}_{15}$ are; 0\%, 5\%, $10 \%$ and $15 \%$ Bamboo Leaf Ash replacements The result above indicates OPC/BLA blended cement concrete at 10\% replacement performed better in $\mathbf{N a}_{2} \mathbf{S O}_{4}$ solution over that of OPC concrete cured in the same medium solution. The OPC concrete in $\mathbf{N a}_{2} \mathbf{S O}_{4}$ solution shows sign of strength loss from 23.64 to 21.82 .

Figure 5.0: Compressive strength of samples in water and $\mathrm{Na}_{2} \mathrm{SO}_{4}$ at 28 day hydration period.

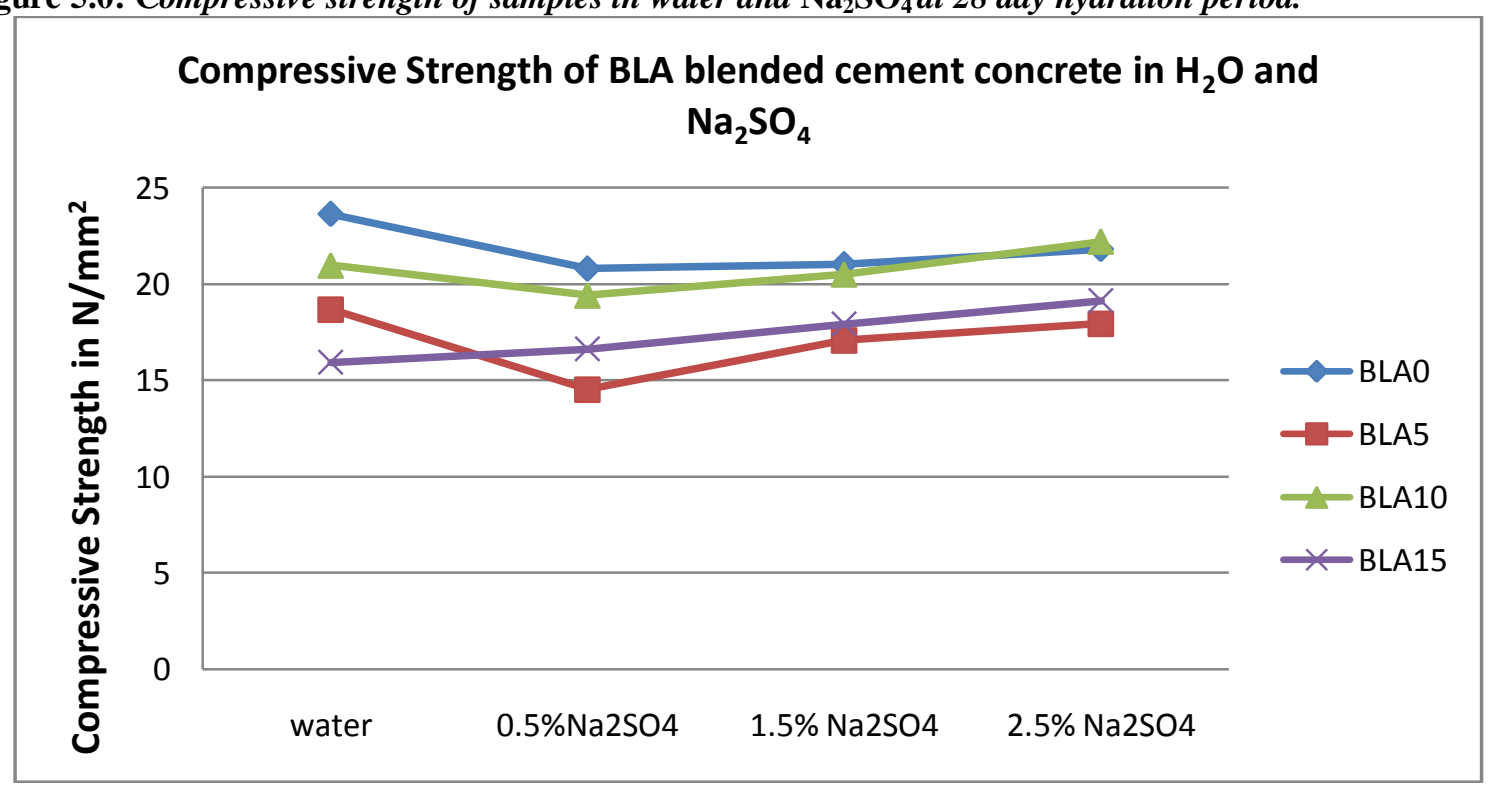


Table 5.5: Compressive Strength of BLA blended Cement Concrete Cured in water and 0.5\%, $1.5 \%$ and $2.5 \%$ Solution of $\mathrm{MgSO} 4$ at 28 days of hydration.

\begin{tabular}{|l|l|l|l|l|}
\hline \multirow{2}{*}{ Description } & \multicolumn{4}{|l|}{ Compressive Strength In $\left(\mathrm{N} / \mathbf{M m}^{2}\right)$} \\
\cline { 2 - 5 } & water & $\mathbf{0 . 5 \%} \mathbf{M g S O}$ & $\mathbf{1 . 5 \%} \mathbf{M g S O}$ & $\mathbf{2 . 5 \%} \mathbf{M g S O}$ \\
\hline BLA $_{\mathbf{0}}$ & 23.64 & 19.20 & 17.15 & 17.09 \\
\hline BLA $_{\mathbf{5}}$ & 18.69 & 17.03 & 16.22 & 15.54 \\
\hline BLA $_{\mathbf{1 0}}$ & 20.98 & 18.98 & 19.48 & 21.46 \\
\hline BLA $_{\mathbf{1 5}}$ & 15.93 & 17.21 & 15.16 & 15.24 \\
\hline
\end{tabular}

$\mathrm{BLA}_{0}, \mathrm{BLA}_{5}, \mathrm{BLA}_{10}$ and $\mathrm{BLA}_{15}$ are; 0\%, 5\%, $10 \%$ and $15 \%$ Bamboo Leaf Ash replacements

The result in table 5.5 above shows loss in compressive strength of OPC and 5\% BLA replacement concrete cured in MgSO 4 solution over the concrete cured in water at the age of 28 days hydration. While the concrete with BLA blended cement concrete increases in its compressive strength with reasonable value, especially at $10 \%$ BLA replacement.

Figure 6.0: Compressive strength of samples in water and $\mathrm{MgSO}_{4}$ at 28th day

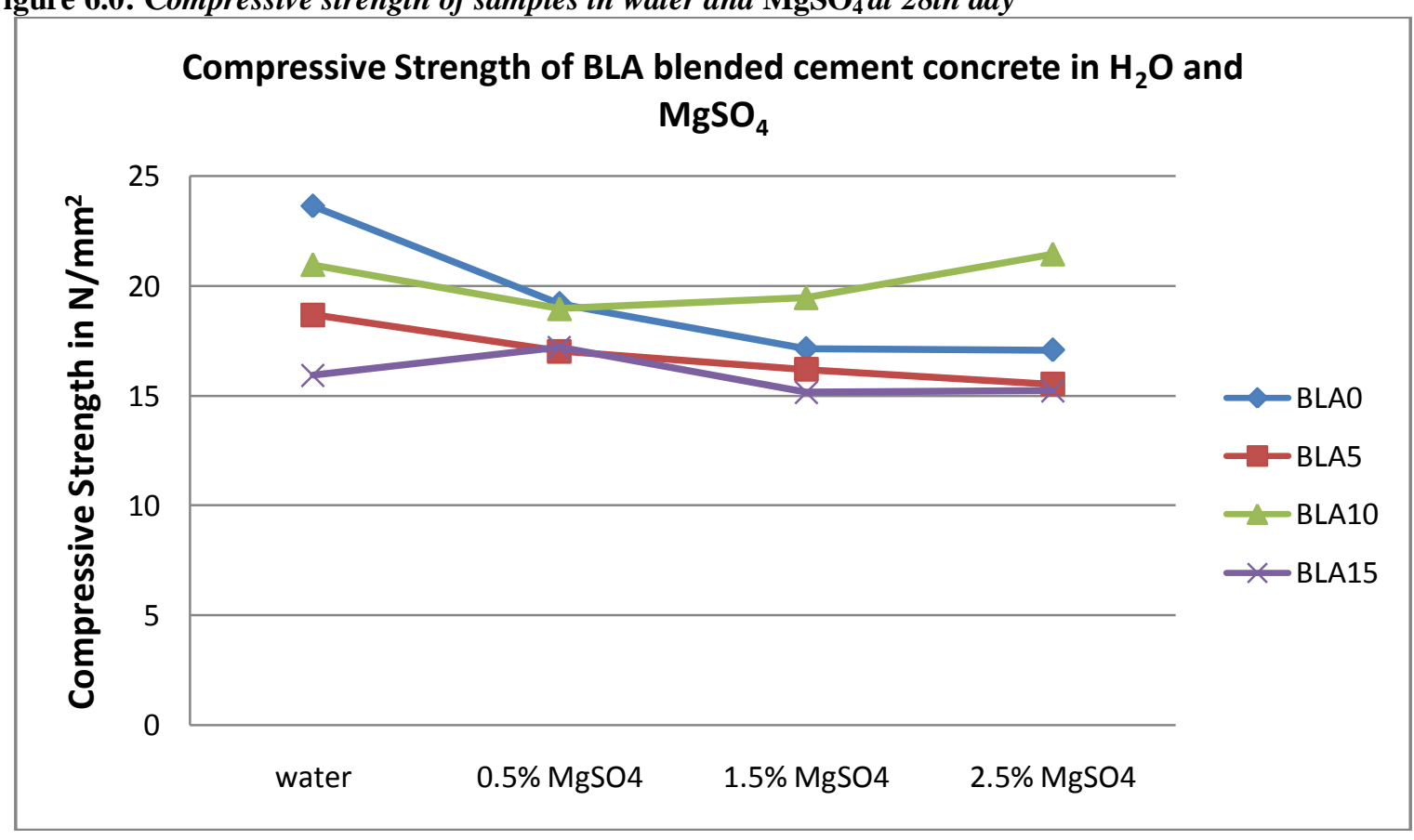

IV. CONCLUSION

From the result of the tests and analysis carried out, the following conclusions were drawn:

$>$ The Bamboo leaf Ash blended cement concrete haven proven resistance to magnesium sulphate, sodium sulphate and calcium sulphate media and would perform better in soils containing these media $\left(\mathbf{M g S O}_{4}\right.$, $\mathrm{Na}_{2} \mathrm{SO}_{4}, \mathrm{CaSO}_{4}$.).

$>\mathrm{OPC}$ has the higher specific gravity than that of BLA, and this is responsible for the decrease in slump value obtained as the percentage of BLA replacement increases.

$>$ The compressive strength value of the BLA/OPC blended concrete up to $10 \%$ replacement level performed better and would be acceptable and considered as a good development for construction of masonry walls and other construction activities in any sulphate environment.

\section{REFERENCES}

[1] Olutoge F.A, Buari T.A and Adeleke J.S (2013) "Characteristics Strength and Durability of Groundnut Shell Ash (GSA) Blended Cement Concrete in Sulphates Environment” International Journal of Scientific Engineering Research (IJSER) volume4, issue7

[2] Ogundipe T.M (2014) "Durability of Bamboo Leaf Ash Blended Cement Concrete in Sulphate Environment", Unpublished M.Sc. thesis in the department of civil engineering, University of Ibadan, Nigeria. 
[3] Almesfer, N., Haigh, C., andIngham, J. (2012). Waste paint as an admixture in concrete. Cement and Concrete Composites, 34(5), 627-633.

[4] Ismail, Z. Z., andAl-Hashmi, E. A. (2011). Assessing the recycling potential of industrial wastewater to replace fresh water in concrete mixes: application of polyvinyl acetate resin wastewater. Journal of Cleaner Production, 19(2-3), 197-203.

[5] Juenger, M. C. G., Winnefeld, F., J.L. Provis and Ideker, J. H. (2011). Advances in alternative cementitious binders. Cement and Concrete Research. 41(12), 1232-1243.

[6] Schneider, M., Romer, M., Tschudin, M. and Bolio, H. (2011). Sustainable cement production--present and future. Cement and Concrete Research. 41(7), 642-650.

[7] Akaninyene A. and Olusola K.O, (2012), "Effect of Different Sulphate Types and Concentrations on Compressive Strength of Periwinkle Shell Ash Blended Cement Concrete" International Journal of Engineering \& Technology IJET-IJENS Vol: 12

[8] Malhotra, V. M., \& Mehta, P. K. (2004).Pozzolanic and Cementitious Materials. London:

[9] Prasad, J., Jain, D.K. and Ahuja, A.K. (2006) "Factors Influencing the Sulphate Resistance of Cement Concrete and Mortar", Asian Journal of Civil Engineering (Building and Housing), 7 (3), 259-268.

[10] B.A. Alabadan, C. F. Njoku and M. O. Yusuf (2006) "The Potentials of Groundnut Shell Ash as Concrete Admixture". Agricultural Engineering International: the CIGR E journal. Manuscript BC 05 012, Vol.VIII. February, 2006.

[11] ASTM C191 (1992). Test for Time Setting of Hydraulic Cement. America Standard of Testing Material International 1916 Race Street, Philadelphia, Pa 19103, USA

[12] Buari T.A, Ademola S.A and Ayegbokiki S.T (2013) "Characteristics Strength of groundnut shell ash (GSA) and Ordinary Portland cement (OPC) blended Concrete in Nigeria", International Organization of Scientific Research (IOSR) Volume 3, Issue 7, july-2013.

[13] Kamang et'al, (2001), The Effects of Chemicals on the Properties of OPC/PFA Concrete. Nigerian Journal of construction Technology and Management 4 (1). 